\title{
Prácticas y discurso intelectual en ONG's educacionales opositoras a la Dictadura chilena. Los casos del CIDE y PIIE
}

\author{
Practices and intellectual discourse in educational NGOs opposed to the \\ Dictatorship. The cases of CIDE and PIIE
}

\author{
Sebastián Neut Aguayo*
}

\begin{abstract}
Resumen: El objetivo del artículo es analizar la transformación de las prácticas y del discurso intelectual desarrollado en el seno de ONG's relacionadas al ámbito educacional durante la Dictadura, dando énfasis a dos instituciones: el Centro de Investigación y Desarrollo de la Educación (CIDE) y el Programa Interdisciplinario de Investigaciones en Educación (PIIE). Desde el punto de vista analítico el texto recupera la perspectiva de la historia social de las ideas, vinculando el contexto político y social con el propiamente intelectual. Fue revisada la investigación publicada por las dos ONG's y se realizaron dos entrevistas a integrantes en la época de CIDE.
\end{abstract}

Palabras clave: Dictadura chilena, educación, consenso en educación, discurso intelectual, ONG's en Dictadura.

\begin{abstract}
The objective of the article is to analyze the transformations of the practices and intellectual discourse developed in NGOs related to the educational field during the Dictatorship, emphasizing two institutions: Centro de Investigación y Desarrollo de la Educación (CIDE) and Programa Interdisciplinario de Investigaciones en Educación (PIIE). From the analytical point of view the article emphasizes the perspective of social history of ideas, linking political and social context with the intellectual one. Were researched the most of publications of the NGOs and two interviews were conducted with CIDE members during that time.
\end{abstract}

Keywords: Chilean dictatorship, education, consensus in education, intellectual discourse, NGO's in Dictatorship.

Recibido: 2 diciembre 2017

Aceptado: 22 enero 2018

\footnotetext{
* Chileno. Estudiante Doctorado en Educación Katholieke Universiteit Leuven, cuestión posible gracias a beca financiada con el esfuerzo del trabajo en Chile. Asociado al proyecto Fondecyt $\mathrm{n}^{\circ} 1110428$. Una versión muy preliminar fue desarrollada en el marco de una tesis de magíster en historia USACH, co-dirigda por los profesores Patricio Miranda y Cristina Moyano, a quienes agradezco lectura crítica y apoyo. Correo electrónico: sgneut@uc.cl. La ayudante de investigación Dominique Méndez colaboró en la recopilación de fuentes, edición y realización de importantes comentarios al texto.
} 


\section{Introducción}

La producción académica e intelectual que estudia las ONG's educacionales durante la Dictadura es escasa ${ }^{2}$, cuestión que no sucede en el caso de otras vinculadas a la investigación política y económica del período. De hecho, solo un trabajo, de María Inés Picazo $^{3}$, ha destinado un esfuerzo importante a hacerlo con las más importantes en cantidad de producción e incidencia académica y política: el Centro de Investigación y Desarrollo de la Educación (CIDE) y el Programa Interdisciplinario de Investigaciones en Educación (PIIE). El estudio de estas instituciones dice relación con la posibilidad de entender la agenda educativa que tomaría el primer gobierno concertacionista $-\mathrm{y}$ los subsiguientes -, ya que dotarían al campo de referentes conceptuales y, cuestión no menor, de responsables de políticas ${ }^{4}$. En la medida en que parte importante del paradigma generado en tal contexto se encuentra vigente, el texto intenta dar pistas que permitan comprenderlo ${ }^{5}$.

Para Picazo en el seno de estas ONG's se produjo tras el golpe de Estado una crisis de los referentes ideológicos que hasta ese momento sustentaban y, a partir de esta, un aprendizaje político de mediano plazo que logró fraguar en una nueva matriz disciplinar. Desde el punto de vista ideológico, los intelectuales entendieron que no debían estudiar el sistema educacional con "anteojeras" ideológicas y, complementariamente, que había que extraer a tal variable del sistema educacional mismo. Lo anterior suponía observar el fenómeno educacional desde una neutralidad valorativa que permitiese interpretarlo de manera científica, cuestión que también debía fundamentar el diseño e implementación de sus políticas. Desde este último punto de vista, tal matriz fue asociada al "pragmatismo", el

\footnotetext{
${ }^{2}$ Respecto de una de ellas ver Mario Garcés, "Las ONG, la educación popular y la política en los años 80: el caso de Eco, educación y comunicaciones". Marcelo Mella (ed.) Extraños en la noche. Intelectuales y usos políticos del conocimiento durante la transición chilena, Santiago de Chile, Ril editores, 2011. Y Cristina Moyano Barahona, ONG y conocimiento sociopolítico durante la Dictadura: la disputa por el tiempo histórico de la transición. El caso de los Talleres de Análisis de Coyuntura en ECO, 1987-1992. Revista Izquierdas, $\mathrm{n}^{\circ}$ 27, Santiago de Chile, abr. 2016.

${ }^{3}$ María Inés Picazo, Las políticas escolares de la Concertación durante la transición democrática. Santiago de Chile: Ediciones UDP, 2013. Leonora Reyes también las ha estudiado en tal contexto, pero enfatizando la incursión práctica de estas en el campo de la educación popular y de los movimientos de renovación pedagógica, sin dar centralidad a la dimensión intelectual. Leonora Reyes, Movimiento de educadores y construcción de política educacional en Chile (1921-1932 y 1977-1994). Santiago, Facultad de filosofía y humanidades, escuela de posgrado Universidad de Chile, 2005. Tesis para optar al grado de doctora en historia con mención en historia de Chile

${ }^{4}$ Entre los integrantes de estas ONG's que pasaron a conformar el equipo del ministro de educación de la transición estuvieron el Jefe de Gabinete, Carlos Eugenio Beca (ex director del PIIE); el encargado de las relaciones internacionales, Ricardo Hevia (ex PIIE); el encargado del programa MECE, Cristian Cox (ex CIDE); la encargada del tema género y educación sexual, María de la Luz Silva (ex PIIE); el director del P900, Juan Eduardo García Huidobro (ex CIDE), y el encargado de las relaciones con el magisterio, Iván Núñez (ex CIDE y PIIE).

${ }^{5}$ La importancia de estas instituciones en el sistema educacional actual resulta, aunque menor en relación a la que tuvieron durante la década de 1990, importante. La actual ministra de Educación, Adriana Delpiano, fue durante años integrante de CIDE y de PIIE, mientras que el actual premio nacional de Educación (2017), Abraham Magendzo, está vinculado al PIIE desde al menos 3 décadas.
} 
que, a su vez, permitió apreciar con distancia y apertura crítica el legado histórico del desarrollo de las políticas educacionales implementadas en Chile hasta ese momento, cuestión que se tradujo en depreciar el rol rector y administrador del Estado en el campo y relevar como contraparte el de los privados y de la sociedad civil. Por lo mismo, permitió ponderar como (potencialmente) positivas varias de las políticas implementadas por la Dictadura.

La visión de Picazo, de cualquier forma, emerge idílica e idealizada, llegando a caracterizar a tales ONG's como "templos de conocimiento"6. En alguna medida ello ocurre, tal como plantea Suasnábar para el caso argentino, porque algunos investigadores de la educación "tienden a incorporar 'los valores de los sujetos estudiados, como valores del analista', lo cual lleva a la confusión de mezclar categorías de análisis con otras de identificación"”.

Intentando tener en cuenta esta advertencia, planteamos una tesis que se encuentra casi en las antípodas de la propuesta por la cientista política. Creemos que si bien se produjo una severa crisis epistemológica en el campo educacional como consecuencia de la instalación de la Dictadura, a partir de aquella - y en el estricto campo educacional que refiere a estas dos ONG's -, no se produjo una aprendizaje incremental de mediano plazo. Por el contrario, el contexto y magnitud de represión y convulsión política y social condicionó que las miradas intelectuales fueran muy sensibles a tal desarrollo, dificultando la generación de una evaluación pausada respecto de lo previamente creído y con un ambiente intelectual cambiante en apenas una decena de años. Ello permite explicar que al transcurrir la década de 1980, la confianza depositada en la sociedad civil y sus recursos educativos fue disminuyendo dramáticamente, mientras que la dada al Estado fue aumentando de forma inversa. En la medida en que se empezó a percibir la posibilidad de una eventual transición a la democracia, este sistema político y la participación social en educación empezaron a pivotar como una alerta acerca de la mantención del orden social, cuestión que dio alta importancia a las nociones del consenso y de la gobernabilidad como mecanismos de reducción de complejidad para la toma de decisiones políticas. De manera contradictoria, entretanto avanzaba la década, el pueblo, y sobre todo su extracto popular, empezó a ser considerado bajo una especie de abulia que le impedía valorar y desarrollar proyectos educacionales propios.

Para llevar a efecto la tarea propuesta se requiere de un enfoque que releve los vínculos entre política, sociedad e intelectualidad en perspectiva histórica. Aunque con diferentes nominaciones, a ello apunta la historia intelectual - si seguimos a Dosse ${ }^{8}-\mathrm{y}$ lo que Revel denomina como historia social de las ideas,

\footnotetext{
${ }^{6}$ Picazo, op. cit., p. 261.

${ }^{7}$ Claudio Suasnábar, Intelectuales, exilios y educación. Producción intelectual e innovaciones teóricas en educación durante la última dictadura, Buenos Aires, Prohistoria, 2013, p. 30.

${ }^{8}$ Francois Dosse, La marcha de las ideas, Historia de los intelectuales, historia intelectual, Valencia, Ediciones Universidad de Valencia, 2007.
} 
"una empresa colectiva, diversa, a veces contradictoria. Ella traduce las convicciones, las opciones, los hábitos, pero también las estrategias, las rivalidades y las adhesiones que forman lo habitual de toda comunidad erudita; más allá de esta comunidad, se apoya en recursos de muy diversa índole: recursos institucionales, instrumentos de difusión, expectativas de un público cuya naturaleza y dimensiones pudieron variar profundamente" 9

Para realizar la reconstrucción histórica del proceso fue revisada gran parte de la investigación publicada por CIDE y PIIE y se realizaron dos entrevistas a profesionales que trabajaron en CIDE durante la década de $1980^{10}$.

\section{Surgimiento y primeros años de CIDE y PIIE}

Durante los "largos años sesenta" América Latina se debatió entre la reforma y la revolución. El desarrollo político de los gobiernos que miraban la primera opción estuvo marcado por la impronta de que el "desarrollo" debía basarse en la planeación, cuestión en la que la educación no quedó inmune. En efecto, esta década puede considerarse como "la 'época dorada' de los organismos internacionales dedicados a la educación que, apoyados en el consenso alrededor de la necesidad del planeamiento, ejercerían una profunda influencia en el redireccionamiento de las políticas educativas en la región" ${ }^{12}$.

El caso chileno no fue la excepción. Al alero de la Alianza para el Progreso, la UNESCO, la OEA y la CEPAL, en 1962 el gobierno de Jorge Alessandri creó la Comisión de Planeamiento Integral de la Educación Chilena, antecedente directo de la reforma educacional implementada durante el gobierno de Eduardo Frei Montalva ${ }^{13}$.

El CIDE fue fundado en tal contexto como una manera de apoyar al representante de la educación particular en tal Comisión. En palabras de quien sería su director entre 1969 y 1997, el CIDE nació “como una respuesta sobre la planificación integral de la educación y una contribución de la Iglesia al desarrollo del país"14. Prontamente sobrepasó sus objetivos originales para dar apoyo a proyectos educativos formales y no formales e iniciar proyectos

\footnotetext{
${ }^{9}$ Jacques Revel, Las construcciones francesas del pasado, Fondo de Cultura Económica, México, 2002, p. 20. En cualquier caso, Dosse delimita la "historia social de las ideas" a aquella tradición en la que las nociones de pueblo, bajo pueblo y cultura de elite se entrelazan. Ver Francois Dosse, La marcha de las ideas, Historia de los intelectuales, historia intelectual, Valencia, Ediciones Universidad de Valencia, 2007, p. 128 y ss.

${ }^{10}$ Fueron revisados 30 textos, además de la Revista Cuadernos de Educación -de tiraje regularmente mensual, entre 1969 y 1990.

${ }^{11}$ Eduardo Devés, El pensamiento latinoamericano en el siglo XX. Tomo II. Desde la Cepal al neoliberalismo (1950-1990). Buenos Aires, Editorial Biblos, 2003.

${ }^{12}$ Suasnábar, op. cit., p. 106.

${ }^{13}$ Iván Núñez, Reformas educacionales e identidad de los docentes: Chile, 1960-1973, Santiago de Chile, PIIE, 1990.

${ }^{14}$ Patricio Cariola, “iQuién fue Patricio Cariola?”, informativo Trimestral N ${ }^{\circ} 32$ Proyecto MENTES ACTIVAS Septiembre - Octubre 2004, p. 2.
} 
de investigación, bajo el amparo de la Compañía de Jesús ${ }^{15}$. Desde fines de la década de 1960 mantuvo una vinculación estrecha con el departamento de pedagogía de la Universidad Católica de Chile, inició proyectos de lo que posteriormente fue conocido como “educación popular” y empezó a perfilar su interés por la investigación educativa ${ }^{16}$.

El modelo modernizador del sistema educacional entró en severos cuestionamientos junto con el arribo al gobierno en 1970 de un nuevo bloque histórico de poder, el que favoreció en la balanza política al polo de la revolución. En tal contexto (1971) nació el $\mathrm{PIIE}^{17}$, como un organismo dependiente de la rectoría (no de la escuela de educación) de la Universidad Católica de Chile, desarrollando investigaciones en el contexto de cambios educativos propuestos por el gobierno popular. En aquella época, "mientras que el CIDE enfatizaba el estudio de la educación privada y el desarrollo de la educación no-formal; el PIIE [lo hacía con] la educación formal en todos sus niveles". Con todo, en ambos centros "primó una investigación denunciatoria, de fuerte crítica a la escuela y al sistema social"18.

La publicación CIDE Cuadernos de Educación ilustra tal apreciación. Por ejemplo, algunos de sus títulos de la época fueron "Tres experiencias de educación surgidas de la revolución (Cuba, China, Chile)"19 "Educarse es romper cadenas" ${ }^{20}$ y "El debate sobre la ENU y la educación...no ha muerto"21, además de incluir entrevistas a intelectuales del tenor de Paulo Freire ${ }^{22}$.

\section{El golpe militar y los primeros años de la Dictadura (1973-1977)}

La Dictadura instalada tuvo enormes repercusiones en la investigación educacional en particular, y en el sistema educativo en general. A partir del 11 de septiembre de 1973 todas las instituciones del Estado, entre ellas las vinculadas a la educación, quedaron bajo tutela militar. Muchos funcionarios de las diferentes reparticiones involucradas con la educación fueron despedidos, encarcelados, exiliados e incluso asesinados y hechos desaparecer. El Superintendente de Educación entre 1970 y 1973, Iván Núñez (futuro CIDE y PIIE), por ejemplo, fue cesado en sus funciones y en 1976 apresado y torturado. Otros debieron salir al exilio, como el Coordinador General del Centro de Perfeccionamiento, Experimentación e Investigaciones Pedagógicas (CPEIP) entre 1970 y 1973, Rodrigo Vera (futuro PIIE), quien arribó a Buenos Aires.

\footnotetext{
15 Ver CIDE. "Memoria de 20 años". Santiago de Chile: CIDE, 1982; CIDE, Memoria 1996/1997, Santiago de Chile, CIDE, 1997.

${ }^{16}$. CIDE, Memoria de 20 años, op. cit., p. 15.

${ }^{17}$ Reyes, op. cit., p. 234-237; Patricio Cariola, La investigación educacional en América Latina. Santiago de Chile, CIDE, 1991; y el sitio web institucional del PIIE www.piie.cl

${ }^{18}$ Cariola, op. cit., p. 7.

${ }^{19}$ Cuadernos de Educación, "Tres experiencias de educación surgidas de la revolución (Cuba, China, Chile)", $\mathrm{n}^{\circ} 18$, Santiago, 1971.

${ }^{20}$ Op. cit., "Educarse es romper cadenas", n 20, Santiago, 1971.

${ }^{21}$ Op. cit., "El debate sobre la ENU y la educación...no ha muerto", n 29, Santiago, 1973.

${ }^{22}$ Op. cit., $n^{\circ} 26$, Santiago, 1972.
} 
El efecto sobre la investigación educacional tampoco fue menor. Las universidades perdieron financiamiento para la investigación, redujeron sus planteles docentes y cerraron carreras pedagógicas. Por otro lado, debieron salir al exilio una pléyade de intelectuales latinoamericanos que habían llegado a Chile durante las décadas de 1960 y los primeros años de la de 1970 escapando de las dictaduras instaladas en sus respectivos países o atraídos por la instalación en Chile de múltiples centros de pensamiento - como la Facultad Latinoamericana de Ciencias Sociales (FLACSO) y el Instituto Latinoamericano de Planificación Económica y Social (ILPES), asociado a la CEPAL-. A tal expulsión se sumó la de algunas instituciones en las que se desempeñaban: la mencionada FLACSO, por ejemplo, prontamente trasladó su secretaría general a Buenos Aires.

El CIDE, que era dirigido desde 1969 por el jesuita Patricio Cariola, se encontraba en un proceso recomposición identitaria e institucional al momento del golpe de Estado ${ }^{23}$. Como algunos de sus colaboradores, particularmente su director, denunciaron la violación a los derechos humanos cometida por el régimen, la institución perdió todo vínculo con los programas que desarrollaba en la educación formal ${ }^{24}$. Algo semejante sucedió con el PIIE, el que si bien mantuvo su afiliación a la Universidad Católica, lo hizo en una condición de suma marginalidad.

Tras su supresión en 1977, sus investigadores lo asociaron a la Academia de Humanismo Cristiano, institución de índole investigativa y de docencia fundada en 1975 por el cardenal Raúl Silva Henríquez. Esta dio acogida a docentes que habían sido exonerados de las universidades por parte de las autoridades militares. Para quien era el director del CIDE en la época, los programas de investigación de ambas instituciones "se fueron asemejando, tanto temática como metodológicamente" 25 .

De todas formas, durante los primeros años de la Dictadura la investigación fue escasa. Además, se produjo un drástico movimiento en su eje, que se tradujo en la desaparición abrupta de las denuncias y propuestas críticas respecto del orden educacional, para dar un unilateral énfasis a elementos propios de las técnicas pedagógicas, didácticas y metodológicas bajo un enfoque 'tecnológico'. En Cuadernos de Educación abundarían títulos como "Cuando aprender no es fácil"26 y "Experiencias: tía Carola y Plaza sésamo"27. Otro número estuvo dedicado completamente al liderazgo educacional ${ }^{28}$.

De cualquier forma, no se produjo en esos primeros años post-golpe una reflexión acerca de las ideas sostenidas hasta ese momento, tal como sucedía entre la intelectualidad de otros países de la región ${ }^{29}$. Ello se explica, al menos hasta 1976, ya que muchas de las organizaciones educacionales pensaban que la Dictadura sería circunstancial, por lo que no

${ }^{23}$ CIDE, Memoria de 20 años, op. cit., p. 15.

${ }^{24}$ Cariola, op. cit., p.3.Cariola relata que tras proteger y lograr asilar a dos altos dirigentes del Movimiento de Izquierda Revolucionaria “descubiertos" por la Dictadura en 1974, esta obligó a las instituciones escolares formales que mantenían vínculos con CIDE a cortarlos completamente.

${ }^{25}$ Patricio, op. cit., 1991, p. 7.

${ }^{26}$ Cuadernos de Educación, ${ }^{\circ}$ 4, Octubre, 1974.

${ }^{27}$ Op. cit., $\mathrm{n}^{\circ} 41$ y $42,1994$.

${ }^{28}$ Op. cit., $\mathrm{n}^{\circ}$ 46, Mayo, 1975.

${ }^{29}$ Suasnábar, op. cit., p. 34. 
existía, en sentido estricto, una derrota de las ideas previamente defendidas. Junto con esto, es importante considerar que nunca se implementó integralmente el programa educacional de la Unidad Popular, por lo que el sistema se mantuvo bajo la estructura surgida en el gobierno anterior al mencionado. De hecho, dentro de la Dictadura existía una pugna por incidir en el sistema, y una de las facciones asociada al desarrollismo abogaba por la continuidad fundamental del modelo ${ }^{30}$. El mismo PIIE da señales al respecto, al decir que "el 'bajo perfil' de las transformaciones educacionales en relación con el conjunto de mutaciones que se producían en la economía, la sociedad y el Estado, no alentaban tampoco esfuerzos mayores de investigación" 31 . Es más, "la preocupación académica por estudiar los cambios introducidos por el régimen militar en la educación es más bien tardía" 32 . En 1981 dos investigadores de la institución mencionada planteaban que "las modificaciones que se efectuaron entre 1973 y 1979 no han sido sometidas a un proceso de evaluación sistemático que permita emitir juicios fundamentados",33.

Cabe destacar que, si bien no se produjo en ese momento la evaluación de las ideas y procesos educacionales en boga previos al golpe, constituyó un tiempo clave para los que se realizaron posteriormente. Iván Núñez recuerda que tras padecer la cárcel y tortura comenzó "a reflexionar con mucha más libertad, con menos férula ideológica que antes y, bueno, este proceso no quedó definido en ese momento todavía"34. En el caso de estos investigadores, sobre todo de los que protagonizaron la época previa al golpe de Estado, el vínculo entre miedo e ideología se hizo inconmensurable.

\section{La preeminencia de la "educación popular" (1978-1984)}

En los últimos años de la década de 1970 se hace claro que, por decirlo en palabras del investigador Juan García-Huidobro (CIDE), "la emergencia se hace permanente"35. En efecto, a partir de esos años, y con mucha fuerza desde 1979, el régimen se embarcó en su propio proyecto educacional, el que se propuso lograr la "modernización" del sistema a

\footnotetext{
${ }^{30}$ Cristian Cox, Osvaldo Larragaña, Iván Núñez. De los sesenta al Bicentenario: políticas, instituciones y actores del sistema escolar, v. 4. Santiago de Chile: [s. n., s/f.]. Proyecto Anillo Soc 17. Documento borrador sin fecha; Andrea Lagos, Neoliberales, nacionalistas y estatistas. El proceso de disputas del período 19731979; Sebastián Neut, "Control ideológico en los programas secundarios transitorios en Historia y Ciencias Sociales (1974-1981)”, en Educação e Pesquisa ahead of print Epub Aug 21, 2017.

${ }^{31}$ PIIE, op. cit.

${ }^{32}$ PIIE. Las transformaciones educacionales bajo el régimen militar Tomo I. Santiago de Chile, 1984, p. 5. Si bien este texto -que intenta dar una comprensión sectorial y global de los cambios producidos por la Dictadura- es del año 1984, las investigaciones que lo conforman fueron desarrolladas en 1982 fundamentalmente.

${ }_{33}$ Abraham Magendzo y Eduardo González, "Análisis de la educación media técnico profesional”, mimeo, Diciembre, 1981, p. 1.

${ }^{34}$ Entrevista $\mathrm{N}^{\circ}$ 7, 2 de diciembre de 2008 en María Nervi, Iván Núñez Prieto, Trazos y huellas en la educación chilena del siglo XX. Santiago de Chile, Editorial Universitaria, 2013, p. 110.

35 Juan García-Huidobro (ed.), Escuela, calidad e igualdad. Los desafíos para educar en democracia, Santiago de Chile, CIDE, 1989.
} 
partir de la preeminencia del ideario neoliberal ${ }^{36}$. Frente a este contexto de imposición unilateral de un proyecto de reorganización drástica del sistema educacional, los intelectuales destinaron su reflexión a la realización de críticas a tal proyecto, pero además dieron centralidad a la teorización de las propias iniciativas que desarrollaban por fuera de la escolaridad formal, lo que consideraban un nuevo paradigma educacional: la "educación popular".

Respecto de las críticas al modelo impuesto, en un temprano 1978 García-Huidobro planteaba que la política educacional buscaba "legitimar un régimen cuyas características predominantes han sido... la concentración del poder político en la Junta de Gobierno; la concentración del poder social en el grupo que tiene acceso a una plena y autónoma organización: los empresarios" 37 . Con todo, solo a partir de 1979 el tenor de tal comentario se amplificó a las publicaciones de estas ONG's. Durante este año en Cuadernos de Educación se hicieron recurrentes los artículos que enfatizaban la distancia entre el ideario cristiano que supuestamente estaría a la base de las políticas del sistema y sus efectivas consecuencias prácticas ${ }^{38}$. La última edición de ese año sería la más dura: estuvo dedicada completamente a evaluar las políticas educacionales implementadas por el régimen, analizando por primera vez de manera integral la Directiva Presidencial de Educación. Carlos Beca (futuro director PIIE) planteaba que el sistema educacional estaba condicionado "por la privatización, elemento central de la política oficial" 39 . En tal sentido, planteaba que "la tendencia supone romper la noción de un sistema educativo único... se irá diversificando de acuerdo a las posibilidades económicas de los diferentes sectores de la población" 40 .

Lo anterior, proseguía, no implicaría una defensa de la libertad de enseñanza, ya que "el Estado asume una función de control ideológico"41. En suma, "la reestructuración administrativa y la descentralización fluyen de la privatización y carecen del sentido democratizante que pudieron asumir en otros proyectos educativos"42. En 1981 Magendzo

\footnotetext{
${ }^{36}$ En general los investigadores plantean que existe un hito demarcatorio entre la fase previa a 1979 y la que la sucedió -caracterizada por la introducción más potente de las lógicas neoliberales en la educación-, a saber, la Directiva Presidencial Sobre Educación Nacional, publicada en la prensa el 6 de marzo de 1979. Sebastián Neut Aguayo. "Sin una buena educación no hay buenos trabajadores... buenos ciudadanos... buenos chilenos. El sentido de la educación en el proyecto modernizador de la Dictadura chilena (1979-1981)", Cuadernos Chilenos de Historia de la Educación, N 6, Santiago de Chile, 2016.

37 Juan García-Huidobro. La actual política educacional: teoría y práctica. Santiago de Chile: CIDE, diciembre, 1978, p. 11.

${ }^{38}$ Entre otros, ver "Actualidad Educacional”, Cuadernos de Educación, n 87, junio de 1979, p. 164-169; Patricio Cariola, "Privatización, subsidiariedad y libertad de enseñanza", Cuadernos de Educación, $\mathrm{n}^{\circ} 88$, julio de 1979, p. 196-204;

${ }^{39}$ Carlos Beca, Cuadernos de Educación, n 92, 1979, p. 310.

40 Ibid, p. 313.

${ }^{41}$ Ibid, p. 311.

42 Ibid, p. 313.
} 
y González (ambos PIIE) refrendaban las ideas educacionales antes planteadas al decir que "los cambios se encuentran en pleno proceso de consolidación"43.

Tal dinámica intelectual tuvo como contrapartida la valorización teórica de los procesos autoeducativos que se desarrollaban en la época por fuera de la educación formal. Estas prácticas fueron aglutinadas en lo que los intelectuales consideraban un nuevo paradigma: la "educación popular" "44. Una publicación CIDE explicaba en 1985 respecto de tal paradigma que era "nuestra actividad principal" 45 , mientras que Jaqueline Gysling (CIDE) planteaba que ingresó a esta ONG "porque ellos en esos años desarrollaban una fuerte línea de educación popular, que me interesaba por razones políticas"46.

En relación a la reflexión que imponía un contexto inédito de autoeducación, los agentes educacionales planteaban que esta práctica "ha levantado más preguntas que respuestas, no ha logrado dar realmente cuenta de sí mismo" y que, en consecuencia, "con el tiempo se ha visto la necesidad de indagar en forma más sistemática la naturaleza de estas intervenciones, de la cultura de las poblaciones en que tiene lugar, y las dimensiones económicas, socio-políticas que tienen" $" 47$.

Aunque los intelectuales pensaban que la reflexión teórica provenía de algunos dilemas surgidos de la práctica autoeducacional misma ${ }^{48}$, lo cierto que es tenían a la mano un seguro repertorio teórico, asociado fundamentalmente a las obras de Gramsci y Freire ${ }^{49}$, que dieron pronta, sistemática y muy teórica respuesta a sus interrogantes. De Paulo Freire, por de pronto, se dijo que "puede ser llamado 'maestro' por todos los que buscamos una educación popular en América Latina" $"$.

En agosto de 1980 el integrante del CIDE recién referido, junto a Sergio Martinic, planteaban que la "educación popular" debía ser comprendida "como una práctica

\footnotetext{
${ }^{43}$ Eduardo González y Abraham Magendzo, Análisis de la educación media técnico profesional, Santiago de Chile, PIIE, 1981, p. 1.

${ }^{44}$ Robert Austin escribió un libro titulado "The State, Literacy and de Popular Education in Chile, 19641990". Tal como su título lo indica, vincula la noción de "educación popular" a las iniciativas que se levantaron desde el Estado y no al concepto aludido en la reflexión estudiada. Robert Austin, The State, Literacy and de Popular Education in Chile, 1964-1990, Lexington Books, Estados Unidos, 2003.

${ }^{45}$ CIDE. Memoria de 20 años, op. cit., p. 20.

${ }^{46}$ Entrevista con Jaqueline Gysling, enero de 2015, Santiago de Chile.

${ }^{47}$ CIDE. Memoria de 20 años, op. cit., p. 21.

${ }^{48}$ Es sabido que la educación popular bebe de la tradición cristiana implicada en los movimientos de base y teológicos pre y postconciliares. A la "pedagogía de la liberación” freiriana, de hecho, antecedía una "teología de la liberación”, cuyo mayor aporte a la reflexión en su campo fue la comprensión de que toda teología que pretendiese observar la sociedad no podía sino desarrollar su corpus teórico a partir de las preguntas que la misma realidad social le demandaba, bajo una comprensión de esta como "desgarrada". Además del texto icónico que dio origen a la "teología de la liberación" de Gustavo Gutiérrez, quien sistematizó una metodología teológica en tal sentido fue Clodovis Boff.

${ }^{49}$ Eduardo García Huidobro se encargó de desarrollar una síntesis operativa de los postulados de ambos autores. Ver Juan Eduardo García Huidobro, "Paulo Freire y la educación de los adultos como acción cultural", mimeo, CIDE, 1982. Las ideas de Antonio Gramsci desarrolladas en su tesis de doctorado en Lovaina circularon en diferentes formatos. Por ejemplo, ver sus escritos en la revista Mensaje de 1978 y 1979 dedicados al tema bajo el pseudónimo Tomás Valdivia.

${ }^{50}$ García, op. cit., 1982, p. 4.
} 
educativa que se inscribe al interior de un proceso más amplio, que busca que los sectores populares se constituyan en un sujeto político conciente [sic] y organizado". En esta línea, compartía "las finalidades generales de la lucha del pueblo por transformar la sociedad [y] se plantea como una ayuda para la realización de esa tarea" ${ }^{\text {. }}$. Como tal, era considerada como contraria a la formal e impuesta por el Estado.

En tal contexto para los investigadores la noción de hegemonía proveniente de la obra de Antonio Gramsci resultó central:

"Como Gramsci advierte, la supremacía de los sectores dominantes se basa en la función que ellos ejercen en el seno de la actividad económica, recurre a formas coactivas y represivas de dominio, pero no se agota allí... el concepto de hegemonía busca indicar que los sectores dominantes no sólo son dominantes sino que llegan a ser también dirigentes. Vale decir, los grupos sociales dominantes logran una supremacía también en el plano cultural, intelectual y moral" ${ }^{152}$.

Por ello, "la definición e implementación de una política educacional no sólo refleja los valores de la clase - o alianza de clases - en el poder, sino que constituye un elemento estratégico de vital importancia para reproducir el sistema de dominación-hegemonía"53. En ese sentido, el objetivo de la "educación popular" no sería otro que el de generar una nueva hegemonía, cuestión que ponía en el centro de las preocupaciones político educacionales la dimensión cultural. Si el dominio de clase se ejercía también mediante las formas de transmisión cultural, eso

“permite valorar ampliamente la educación popular como acción política. La búsqueda de una sociedad distinta no puede ya ser pensada como un mero cambio económico, por importante que sea este cambio, ni como un puro cambio de manos del aparato estatal coercitivo. Las exigencias y necesidades que surgen en el terreno económico deben encontrar su expresión eficiente en la creación de una nueva voluntad colectiva, capaz de actuar y de pensar la sociedad de modo distinto" 54 .

De esta forma, el sentido último de la "educación popular" era el de aportar a la superación de "los límites de clase económica, llegándose a la constitución de una clase política cuya principal característica es su capacidad en forma universal". En consecuencia, respecto del saber popular, resultaba fundamental el papel de lo que Freire denominaba 'concientización', según el cual 'la criticidad aparece ligada a la realidad y posibilidad de participar en forma autónoma e independiente en la producción de la historia"55.

\footnotetext{
${ }^{51}$ Juan García Huidobro y Sergio Martinic, "Intento de definición de la educación popular". En García y Martinic, "Educación Popular en Chile: Algunas proposiciones básicas", Ponencia presentada al Seminario Investigación-acción y educación popular en Chile, Santiago de Chile, CIDE, 1980, p. 1.

${ }^{52}$ García y Martinic, op. cit, p. 3.

${ }^{53}$ Hernán Pozo, Orientación cultural y educación chilena (1973-1981), Santiago de Chile, CIDE, 1982, p. 38.

${ }^{54}$ Idem.

${ }^{55}$ García y Martinic, op. cit, p. 14.
} 
Esta relación pedagógica transformaba también el mecanismo tradicional de la relación profesor/estudiante. Como "es a partir de esta referencia a la situación y a la vida y práctica que debe ser concebido el rol y la tarea del educador popular... es posible decir que el educador popular, antes de educar, es educado por el pueblo... El educador asume el proyecto popular alternativo, se hace parte de él"56.

En síntesis, en ese tiempo los intelectuales destinaron su reflexión a la realización de críticas a las políticas que estaba impulsando la Dictadura en educación formal, pero se caracterizó, sobre todo, por dar centralidad a la problematización teórica de la "educación popular".

Sin embargo, hacia 1983 y 1984 - en un contexto en el que las fuerzas políticas habían comenzado a generar un mayor peso dentro del debate público - el tema de “educación popular" empezó a ser disputado por el de la educación formal en los términos del posible fin del Estado docente y del inicio del modelo subsidiario y neoliberal en educación. En 1983 García Huidobro abría la siguiente duda: “¿Lo que se ha estado haciendo en educación popular sigue teniendo vigencia en momentos de mayor activación e interlocución política, a nivel de la sociedad?"57.

\section{El consenso en educación (1984-1987)}

Aunque el proyecto dictatorial para la educación había partido en 1979 y se había consolidado institucionalmente a partir de la dictación de una nueva Constitución política al año siguiente ${ }^{58}$, la reflexión teórica en torno a este proceso solo adquirió un mayor impulso en la medida que los efectos prácticos de tales cambios resultaban ineludibles en el sistema educacional, sobre todo a partir de mediados de la década de $1980^{59}$. Asimismo, en el contexto temporal estudiado la crisis económica iniciada en 1983 comenzaba a ser superada - cuestión que también tuvo implicancias a nivel educativo, ya que fue reactivada la municipalización de la educación - y, como contraparte, los partidos políticos empezaban tener mayor preeminencia dentro del debate de oposición a la Dictadura, generando intentos de establecer puentes de conexión con esta que permitieran iniciar un diálogo político.

En ese contexto, se empezó a producir un giro radical en los temas y debates que se suscitaban en ambas ONG's, articulados por la nueva importancia que empezó a adquirir la reflexión en los contornos de la educación formal. Si bien la "educación popular" se

\footnotetext{
${ }^{56}$ García y Martinic, op. cit. , p. 15.

57 Juan García. "Perfilando una pregunta: ¿aporte político de la educación popular?” Santiago de Chile: CIDE, 1983, p. 3.

${ }^{58}$ Neut, 2016, op. cit.

59 Entre 1980 y 1981 el ministerio hizo un recambio general de los planes y programas de todo el ciclo escolar; desde 1981 fue liberalizado el mercado de la educación superior, desmembradas las universidades del Estado y las carreras pedagógicas deslindas de las "profesionales", pudiendo ser impartidas por institutos profesionales; mientras que a partir de 1982 se inició el proceso de municipalización de la educación escolar desligando al nivel central del Estado de su responsabilidad sobre esta en sus aspectos administrativos- y se introdujo la competencia entre esta y la privada.
} 
mantuvo como una práctica difundida, este paradigma empezó a ser eclipsado por la idea de que la "cultura escolar" debía ser estudiada al nivel de las prácticas cotidianas mismas de las instituciones escolares formales. De esta forma, se produjo un desplazamiento en torno al tema de la "cultura", ahora radicado, a nivel general en el sistema regular de enseñanza, y a nivel particular, en la sala de clases. Además, la dimensión política de la educación empezó a concebirse como la instalación de "relaciones más humanas" en las instituciones escolares y ya no como un proyecto ético-político que las impugnaba en sí.

“¿Debe el profesor hacer política?” preguntaba en su título un editorial de abril de 1984 de la revista Cuadernos de Educación. Para la institución era importante reconocer que tenían que "reaprender lo democrático"60. A continuación, era planteado que existían dos esferas complementarias "en el accionar político: el relacionado con el Poder estatal y el relativo a la construcción cotidiana de una sociedad democrática. Esta distinción es necesaria para no reducir el hecho de "hacer política" solamente al problema del poder"61.

En este sentido, la democracia no era un mero "problema de instituciones políticas democráticas. Es más que eso, es la construcción de relaciones no autoritarias, no alineadas entre los individuos"62. Similar a lo anterior, en la edición de marzo-abril de 1984 de la revista de la disidente Asociación Gremial de Educadores de Chile (AGECH), Martín Miranda (CIDE) alineaba el tema de los derechos humanos a tal posición. Señalaba que "de nada serviría realizar un afinado análisis del autoritarismo, en un marco de relaciones y metodologías autoritarias" al igual que "revisar las virtudes de la democracia en un contexto de experiencias educativas anti-democráticas"63.

La importancia dada al microcosmos de la sala de clases y/o de la escuela, específicamente de su cotidianeidad, permitía, según estos autores, radicar el debate educacional en un nivel poco problemático para la gran política. En la editorial antes mencionada se leía lo siguiente: "Los profesores, en su mayoría, evitan abordar en la escuela el tema político. Hablar de política hasta asusta. Sin embargo lo que estamos evitando no es más que el hablar de un ámbito o dimensión de lo político: el que se refiere al Poder estatal, al régimen establecido"64. Quedaba otro espacio, el de las relaciones humanas desplegadas o por desplegar en los recintos educacionales en los que la política, entendida como ethos cultural democrático, sí podía ser experimentada. En efecto, siendo importante para el profesor su preparación y consideración de la dimensión del poder en la política, "está la otra, la de la construcción cotidiana de una sociedad democrática y en ella hay un campo de inmensa riqueza para la acción del profesor"65.

Con todo, lo anterior no suponía que había que contraponer ese poder localizado ni ningún otro (como en el modelo de la "educación popular") al del Estado. Por el contrario,

\footnotetext{
${ }^{60}$ Editorial, Cuadernos de educación, n 134, Santiago, 1984, p. 43.

${ }^{61}$ Ibid, p. 43.

${ }^{62}$ Ibid, p. 44.

${ }^{63}$ Martín Miranda. "La escuela y el desafío de los derechos humanos”, Revista Signos, N $^{\circ}$ 2, Chile, marzoabril, 1982, p. 25.

${ }^{64}$ Editorial, Cuadernos de educación, op. cit., p. 42.

${ }^{65}$ Ibid, p. 44.
} 
había que intentar, en la dimensión de la gran política, hacer propuestas educacionales que pudiesen ser implementadas en el contexto dictatorial mismo. Sin embargo, ello tenía como condición de posibilidad que la Dictadura se abriese a la opinión de los intelectuales opositores. La noción que articuló tal posibilidad fue la del consenso.

El evento que dio cuenta de manera más clara de este nuevo enfoque y pretensión fue la realización de un foro acerca de la educación llevado a cabo entre noviembre y diciembre de 1984. En este el CIDE reunió a representantes de gran parte del arco intelectual y político existente ${ }^{66}$ en la búsqueda de puntos educativos en común, situación que se produjo bajo un contexto particular: el Estado de sitio.

El objetivo de los encuentros era dar curso a la "discusión en la dirección de reestablecer la política donde ha estado imperando la guerra", cuestión que, en los hechos, implicaba "la producción de consensos respecto a criterios de política educacional" 67 . El "consenso" como noción articuladora fue, paradojalmente, considerado como una aporía, como mencionaba el prefacio del libro que recopiló la transcripción de las reuniones: "el consenso es históricamente imposible pero la paz estable sin cierto consenso tampoco es posible"68. En este sentido, para los promotores de tal iniciativa la política educacional no debiese ser "ingenua respecto a la omnipresencia del conflicto y del uso del poder"; sin embargo, debe fijar "límites al disenso al optar por la paz y la no exclusión como criterios reguladores fundamentales de las prácticas de construcción de orden" 69 . El consenso, en tal sentido, no fue vinculado a la democracia en términos del tránsito histórico hacia un modelo político de tal tipo, sino que al de una "cultura" de la paz y del diálogo.

Se debe considerar que tales planteamientos se producían en un contexto en el que toda discusión educacional al nivel público estaba condicionada por un marco en el que la violencia del Estado se presentaba de manera cotidiana y permanente. Cristian Cox, a la sazón intelectual asociado al CIDE, comenta: "no éramos nada. No había democracia, no había debate, no había prensa, y era la primera ocasión en que el gobierno, o personal de gobierno, conversaba abiertamente con su oposición, entonces los temas estaban totalmente determinados por lo que era la agenda de gobierno, no por nuestra agenda"70.

\footnotetext{
${ }^{66}$ Durante seis lunes de noviembre y diciembre de 1984 se reunieron personas vinculadas directamente con la educación que abarcaban un amplio espectro ideológico y político. Entre los asistentes vinculados a la derecha y al oficialismo se encontraban, entre otros, Gonzalo Vial Correa, ex ministro de la dictadura en la cartera de educación; Nicolás Majluf, Coordinador Nacional del Programa de Evaluación del Rendimiento de la Educación (PER), y María Teresa Infante, Superintendente de Educación. Entre los vinculados al mundo democratacristiano y de la renovación socialista, Ernesto Schiefelbein, ex Director de la Oficina de Planeamiento durante la reforma educacional del gobierno de Frei Montalva; José Brunner, en ese momento director de la Facultad Latinoamericana de Ciencias Sociales (FLACSO), Juan García-Huidobro, en ese momento director del Programa de Investigaciones del CIDE, e Iván Núñez, ex Superintendente de Educación y PIIE, en ese momento.

${ }^{67}$ Cristian Cox (ed.). Hacia la elaboración de consensos en política educacional: actas de una discusión, Santiago de Chile, CIDE, 1985, p. 3.

${ }^{68}$ Ibid, p. 3.

69 Ídem.

${ }^{70}$ Entrevista al sociólogo Cristian Cox, marzo de 2015.
} 
Asimismo, es importante considerar que en un escenario "de irrupción de la protesta, la aparición del miedo al descontrol y al enfrentamiento hizo surgir, aparejado al debate sobre la democracia, el debate sobre el consenso"71. En síntesis, esta noción, aplicada a la educación, vino a operar para los intelectuales como concepto disipador de una violencia que acosaba tanto desde el Estado como desde la sociedad.

En la misma línea teórica elaborada en torno al rol político del profesor y de la escuela, los promotores de la iniciativa proponían que existía una dimensión más "concreta" de la reflexión y de las políticas educacionales que permitía delimitar la confrontación:

"La modalidad de funcionamiento elegida procuró abordar los problemas desde sus rasgos más concretos y específicos evitando que desde el inicio el debate ideológico fuera el foco de discusión. No es que 'lo específico y concreto' de por sí fuera visto como un nivel menos atravesado por valoraciones... pero sí es un nivel donde los límites entre lo que une y separa a los grupos son más tenues y flexibles"72.

El consenso no solo se erigió como condición ético-política, sino que también fue vinculado a cuestiones intrínsecas de las posibilidades de éxito en el mejoramiento de la educación, es decir, fue asumido como un componente técnico y natural a los procesos de adelanto educacional. El texto de la última sesión lo plantea del siguiente modo: "El consenso es una condición básica de la estabilidad en las políticas. La mejora de la calidad, desde múltiples planos, tiene que ver en forma muy importante con la estabilidad del sistema""73. Patricio Cariola planteaba: "me ha tocado la palabra "cambio" como el gran valor, y ahora, en este seminario, en cambio, lo que se ha insistido es en la necesidad de estabilidad. El consenso gira en gran parte en función de la estabilidad, y la estabilidad en función de la calidad. Las tres cosas aparecen bastante amarradas"74.

Fue bajo tales consideraciones que se produjo la evaluación de las políticas educacionales producidas en los años previos al golpe de Estado. En una sesión del seminario, José Brunner (FLACSO) planteaba que la politización y la polarización en la educación tenían problemas que conocieron "en cierto periodo de nuestra historia, sobre todo del 70 al 73" ${ }^{\prime \prime 5}$. No solo ello, tal articulado discursivo permitía generar un diagnóstico de la situación presente. En palabras de Iván Núñez: "me cuesta ser optimista respecto al consenso", ya que "lo que parece predominar más son las tendencias al conflicto agudo, dijéramos, a la división, al choque ya frontal. Además, la magnitud misma de los problemas educativos complica más todavía"76.

71 Cristina Moyano, "Un acercamiento intelectual histórico-conceptual al concepto democracia En la intelectualidad de la izquierda renovada. Chile, 1973-1990", Revista Izquierdas, n 3, Santiago de Chile, 2012 , p. 5.

72 Cox, 1985, op. cit., p. 8.

73 Ibid, p. 244.

74 Ibid, p. 226.

75 Ibid, p. 129-130.

${ }^{76}$ Palabras de I. Núñez en Cox, 1985, op. cit., p. 229. 
Para estos investigadores la preocupación central en relación a las posibilidades de gobernar el sistema educacional en un potencial tránsito hacia la democracia no se fundaba en las políticas y violencia imprimidas por la Dictadura, sino en las lógicas derivadas de la acción popular presentes en la época. En ellos existía una rara y contradictoria mezcla de miedo a la participación educativa y política junto con una atribución a las mayorías de abulia social y participativa en la educación comunitaria, cuestión que se insertaba en la posibilidad incierta del retorno a un régimen democrático: “¿Se discutió qué significaría la municipalización en el momento en que el país vuelva a un sistema democrático?", preguntaba Brunner ${ }^{77}$. El diagnóstico que permitía o facultaba la unión de las ideas distanciadas era que, al no existir organización ni movilización social propiamente tal en Chile, las mayorías resultaban manipulables políticamente.

Para él la participación política y educativa pasaría por "la actividad de grupos minoritarios capaces de conducir y de ejercer ciertas formas de manipulación de masas en el mejor sentido de la palabra"78. Cristian Cox planteaba en tal línea que "cuando le pidamos a la comunidad local que por favor participe, que por favor diseñemos un currículum, por favor ayúdennos a educar, lo más probable es que nuestras peticiones vengan de vuelta con un gran signo de interrogación"79. Iván Núñez también aplaudía tal visión y explicaba que dejándose

"llevar por el enfoque histórico de don Mario Góngora, del Estado construyendo a la sociedad chilena... en el momento en que se pudiera ofrecer ampliamente y que hubiesen mayores márgenes de libertad, esa participación no sería lo suficientemente asumida por aquellos a quienes nosotros le estamos suponiendo un deseo de participar",

para luego afirmar que temía "que en muchos sectores de nuestra población, por ejemplo en los mismos sectores sociales que hoy día se alzan, que están en la protesta, en el momento que se enfrentan al problema de la escuela, son de los que le dicen a la profesora: "péguele no más señorita, yo la autorizo para que le pegue al niño"" 80 . Brunner proponía frente a tal diagnóstico que

"un freno para la política como politización ha sido en este país la existencia de un cierto centralismo y de un Estado relativamente fuerte, porque eso es lo que logra imponerle barreras a esta sociedad que es bastante incontrolable... que yo creo que a la vuelta de esta situación van a estar presentes con la misma o mayor fuerza" ${ }^{" 1}$.

Ello sería así, abunda Cox, ya que "culturalmente este país nunca ha generado iniciativas educacionales que no pasen por el Estado, por manipulación política, por

\footnotetext{
${ }^{77}$ Palabras de J.J. Brunner en Cox, 1985, op. cit., 129.

${ }^{78}$ Ibid, 170-171.

${ }^{79}$ Ibid, 158-159.

${ }^{80}$ Palabras de I. Núñez en Cox, 1985, op. cit., p. 164-165.

${ }^{81}$ Palabras de J.J. Brunner en Cox, 1985, op. cit., pp. 170-171.
} 
agregación de demanda e intervención estatal en la cúpula"82. Es decir, el Estado, bajo tales reflexiones, se constituía en un motor fundamental del desarrollo educacional, con el cuidado de que no debía ser copado por las demandas populares ni ceder frente a estas.

La presencia de lo que ellos interpretaban era un análisis menos sesgado del desarrollo educacional, que abrió la posibilidad de lograr evaluar "imparcialmente" la acción de la Dictadura. De esta manera, aun criticando algunas de las políticas llevadas a cabo, de manera inédita se valoraron como altamente positivas otras, al menos en el nivel teórico. Iván Núñez, por ejemplo, llegó a afirmar que "yo quisiera declararme fanático de la municipalización" 83 .

Finalmente, tal reconversión ideológica incidió y derivó en la renovación de la interpretación acerca de las finalidades de la educación. De hecho, en las antípodas de la interpretación del modelo de "educación popular", el consenso fue afiliado a la idea de que existía un conocimiento universal que podría facultar el arribo de políticas consideradas legítimas para la globalidad de los actores educacionales:

"La base de una política educacional de consenso descansa sobre el carácter universal de los requisitos culturales para la participación democrática... Objetivos culturales que están "antes" de la ideología. Después de logrados esos mínimos la sociedad podrá disputar sobre qué orientaciones dar a esos recursos simbólicos de base" ${ }^{\$ 4}$.

En la misma línea, Cristian Cox planteaba que "ya no esperamos que la escuela resuelva los problemas de la sociedad, es mucho pedirle” y que solo debía

“enseñar ciertas destrezas básicas y entregar un ambiente social que contribuya a que, especialmente las personas de sectores más pobres, puedan desarrollar una identidad social que les dé capacidad de hablar en grupo, defender sus puntos de vista, preguntar, sentir que los aportes de su cultura valen" $"$.

\section{Gobernabilidad e “ideas-fuerza” en educación (1987-1990)}

En 1987 se abrió un nuevo capítulo en la reflexión educacional, que se desarrolló en un contexto de mayor fortalecimiento de los partidos políticos dentro del debate nacional y

\footnotetext{
${ }^{82}$ Palabras de C. Cox en Cox, 1985, op. cit., p. 158-159.

${ }^{83}$ Cox, 1985, op. cit., 122.

${ }^{84}$ Johanna Filp EN Cristian Cox (ed.), Hacia la elaboración de consensos en política educacional: actas de una discusión., Santiago de Chile, CIDE, 1985. p. 47 y 48. Se debe considerar que Juan García-Huidobro problematizaba - aunque le atraía - tal afirmación: "Me resulta muy atractiva... la idea de que la base de una política educacional de consenso descansa sobre el carácter universal de los requisitos culturales. Sin embargo, quisiera llamar la atención sobre el hecho que esta formulación descansa en el supuesto de que es posible determinar algunos objetivos culturales mínimos indiscutibles dentro de la sociedad, que dan pie para una política educativa bastante estable. Tiendo a creer que esto es posible; pero veo también que esto es posible a condición de aceptar un "empobrecimiento" de la concepción que tenemos de educación”, p. 228. ${ }^{85}$ Palabras de Cristian Cox en Cox, 1985, op. cit, p. 47.
} 
en que la transición a la democracia, vía aceptación de las reglas del juego constitucionales, ya no se percibía simplemente como posibilidad incierta, sino que como más que probable proceso a consumarse. Con este horizonte los intelectuales dejaron de intentar abrir espacios de diálogo con los actores pro-dictadura y empezaron a generar, además de nuevos textos, debates internos - seminarios fundamentalmente - tendientes a precaver y proyectar las políticas educacionales a implementar en el futuro cercano. Desde 1988 los debates y postulados dieron lugar a propuestas programáticas de políticas educacionales.

Junto con una nueva interpretación del consenso -a analizar posteriormente-, empezó a tomar fuerza otra noción: la de gobernabilidad. Dicho en breve, si el consenso apelaba a la coordinación horizontal entre actores, la gobernabilidad lo hacía hacia su coordinación vertical, mientras que, si la primera noción resultaba sinérgica respecto del mejoramiento de la educación, la segunda era capaz de asumir algunas de las "externalidades negativas" que suponía mantener el orden social. En este contexto, en 1987, intelectuales como Iván Núñez ya preveían, por ejemplo, dificultades que podían generarse en el sistema educacional en "un futuro régimen democrático en Chile" gobernabilidad democrática del sector educación: relación entre investigación y política" planteaba "que una indebida atención a los problemas del sistema educacional puede ser un factor que alimente conflictos en este campo, conflictos que pueden tener una fuerza o gravedad suficiente como para desestabilizar un futuro régimen democrático en Chile". Como consecuencia, era indispensable la configuración de "políticas públicas... que permitan neutralizar tal posibilidad $\mathrm{y}$, al mismo tiempo, conviertan a la educación efectivamente en una palanca de consolidación de ese régimen [es decir la democracia] y de consecución y profundización de condiciones de justicia que permitan su perfeccionamiento y estabilidad a largo plazo" $"$.

El relevo de la necesidad de dotar de cuidadas políticas públicas en educación vino a la par con la defenestración teórica de la educación popular. A diferencia de sus posturas de inicios de década, Sergio Martinic (CIDE) planteaba que para los participantes en las iniciativas de educación popular estas "constituyen un particular espacio de estabilidad y de integración en la sociedad... la mantención o la creación de un orden que los integre constituye una orientación práctica fundamental" ${ }^{\prime 88}$. En los comentarios a la ponencia el investigador Guillermo Campero planteaba que los sectores populares deseaban "participar en algún tipo de establishment... Es decir, el estar vinculándose o articulándose a sectores o grupos sociales que tienen poder en la sociedad. Los profesionales, los intelectuales, la Iglesia, los miembros de partidos" $" 89$. De esta manera los educadores populares, en tanto que "son parte de ese establishment son, progresivamente, transmisores de las imágenes, de los

\footnotetext{
${ }^{86}$ Núñez, 1987, op. cit., p.5.

${ }^{87}$ Ídem, pp. 5-6.

${ }^{88}$ Sergio Martinic y Horacio Walker, Profesionales en acción. Una mirada crítica a la educación popular. Santiago de Chile: CIDE, 1988, p. 74.

${ }^{89}$ Guillermo Campero en Martinic y Walker, op. cit., p. 100.
} 
propósitos y de las estrategias que provienen desde [tal]"90. En la base de aquel análisis se encuentra una visión del mundo popular como

"un universo tremendamente heterogéneo, desintegrado, carente a menudo de pautas culturales y sociales articulatorias, por lo que recibe - y así me parece que ha sido la historia de los últimos 20 años- con especial sensibilidad las ofertas constructoras de identidad que vengan desde afuera y que permitan definirle un tipo de espacio social y un tipo de prospectiva social" 91 .

A partir de 1988 los debates dieron lugar a documentos programáticos. En los prolegómenos del plebiscito del 5 de octubre el PIIE publicó "Ruptura y construcción de consensos en la educación chilena"92, texto que fijó su postura institucional frente a tal evento y sus posibles consecuencias en el campo educacional. En la publicación fue establecida una narrativa inédita de la historia reciente de la educación chilena: de la interiorización de la culpa se pasó a la culpabilización del régimen, y se consideró que el golpe de Estado puso fin a una previa época dorada de la educación. Para la institución, hasta antes del golpe de Estado de 1973, "la educación chilena era reconocida como una de las mejores de la región", cuestión que "fue posible gracias a un conjunto de consensos construidos desde comienzos del siglo". Sin embargo, "el régimen militar ha roto esos consensos y ha interrumpido el desarrollo democrático de la educación para remplazarlo por lo que podría denominarse una parodia de modernización" $" 33$.

Con todo, ello no implicó una lectura rupturista en torno a la situación en la que se encontraba el sistema educacional del momento; por el contrario, propusieron que frente a las "parodias de modernización" efectuadas por la Dictadura, había que imponer una real modernización educativa.

La ruptura violenta de los consensos educativos imponía un nuevo imperativo ético y político, a saber, la "reconstrucción de los consensos", lo que equivalía a aglutinar a las fuerzas educativas democráticas en pos de fraguar un proyecto pedagógico unitario. Sin embargo, también emergía una condición muy distinta a la experimentada en la fase anterior en relación a la conceptualización del concepto en análisis: si antes el arribo a consensos no implicaba determinado régimen político, en la nueva interpretación la democracia política emergía como un imperativo de tal reconstrucción. En palabras del PIIE, la reconstrucción de consensos "requiere condiciones democráticas: espacios públicos abiertos, libertad de expresión y de organización, información amplia sobre la realidad educativa, transparencia en los actos gubernativos, respeto a las críticas y a las disidencias y, sobre todo, mecanismos y canales de participación". De todos modos, "nada de ello se logrará de persistir el régimen militar"94. La visión global del PIIE podría sintetizarse en la

\footnotetext{
90 Ibid, p. 101.

${ }^{91}$ Ibid, p. 101.

92 PIIE, "Ruptura y construcción de consensos en la educación chilena", Santiago de Chile: PIIE, 1988.

${ }^{93}$ PIIE. ibid, p. 9.

94 PIIE. ibid, p. 30.
} 
siguiente cita: "en los hechos, el Estado subsidiario en educación es una farsa. Lo que ha prevalecido es el Estado autoritario"95.

El CIDE no quedaba la margen de esto. En 1989 Cristian Cox planteaba que "preguntarse entonces por las relaciones entre el sistema político y la educación no es identificable sin más con un "problema sectorial". En forma muy directa equivale a interrogarse por las dimensiones más profundas de los conflictos y dilemas respecto al orden que tenemos y al orden que queremos como nación" 96 .

El consenso, con todo, implicaba una reducción de divergencia. La operación que permitió consumarla fue suponer que su reconstrucción resultaba, en la práctica, de hacer consientes algunos consensos a los que ya se había arribado: "sobre esta base [de amplios consensos] es posible y necesario abrir debates que permitan la confrontación de opiniones divergentes pero que asuman los consensos mayoritarios"97. En otra sección se planteaba que resultaba necesario "reconstruir consensos sobre el rol del Estado y del sector privado, sobre la ampliación e igualdad de oportunidades, sobre el pluralismo, sobre la libertad de enseñanza y sobre la modernización cualitativa de la educación", para afirmar a continuación que

"salvo en una minoría de dogmáticos del neo-liberalismo y de la seguridad nacional, existen ya amplias coincidencias sobre la necesidad de un distinto tratamiento a los educadores, sobre la descentralización, y respecto a la 'alcaldización' existe casi unanimidad en torno al término de los rectores-delegados y sobre la autonomía de las instituciones de educación superior. Hay amplio acuerdo sobre el destierro de los criterios de mercado como determinantes de la organización y funcionamiento del sistema educativo, especialmente respecto de la educación masiva, la cual debería constituirse bajo una lógica de servicio social. También hay acuerdos en relación con los fines pedagógicos en la educación formal"98.

La elaboración de estas "bases de consenso", realizadas participativa y responsablemente, deberían concluir "en una suerte de gran pacto educacional que permita levantar líneas de política educacional de la nación"99.

Ad portas de la elección presidencial de 1989, PIIE y CIDE expusieron nuevos documentos programáticos ${ }^{100}$, cada vez más anclados en la exposición de "ideas-fuerza". En octubre de ese año el PIIE planteaba que

\footnotetext{
95 PIIE. ibid, p. 26. Negritas en el original.

${ }^{96} \mathrm{COX}$, Cristian. Sistema político y educación en los 80’: medidas propuestas y silencios. En Juan García Escuela, calidad e igualdad. Los desafíos para educar en democracia, Santiago de Chile: CIDE, 1989, p. 8.

${ }^{97}$ PIIE, op. cit., pp. 29-30.

${ }^{98}$ PIIE, op. cit., p. 30.

${ }^{99}$ Idem.

${ }^{100}$ Leonora Reyes plantea que en el CIDE se produjeron diferentes miradas en torno a la manera de enfrentar el tipo de transición propuesta por los partidos políticos y que en el PIIE no sucedió tal situación porque era, en los hechos, un organismo de formación de policymakers e intelectuales orgánicos para el nuevo conglomerado de gobierno. Ver Leonora Reyes, "Movimiento de educadores y construcción de política educacional en Chile (1921-1932 y 1977-1994)", Tesis para optar al grado de doctora en historia con mención
} 
"la inminente transición a la democracia y la más clara configuración de sus características político-institucionales y económico-sociales, han desafiado a los investigadores a preparar y sugerir ya no sólo proposiciones y demandas genéricas, a cumplir en plazos medianos o largos y con una supuesta abundancia de medios, sino esbozos de políticas públicas apropiadas a las características del próximo período de cuatro años" $" 101$.

¿Cuál sería el punto de partida según el PIIE? "La construcción de una nueva educación tendrá un punto de partida: las reestructuraciones modernizantes introducidas especialmente desde 1979-80"102. Para esta organización, frente a las "parodias de modernización" efectuadas por la Dictadura -entendidas estas como propuestas discursivas y formalmente adecuadas (en algunos casos) para enfrentar el problema educativo pero materialmente inadecuadas-, había que llevar a efecto reales y eficientes procesos modernizadores. Para al PIIE algunas políticas debían desecharse, aunque no menciona cuáles, mientras que la mayoría (descentralización, mecanismos de participación social, diversificación de la educación post-secundaria, flexibilidad curricular) ser redefinidas o reorientadas ${ }^{103}$.

Esto suponía un segundo elemento clave, que para el PIIE tuvo una consigna: "no partir de cero" 104 . De manera contradictoria a una interpretación que simultáneamente atribuía al régimen la ruptura de los consensos, la ONG interpretó que los tres gobiernos anteriores habían intentado implantar reformas profundas al sistema educativo sin considerar su derrotero, características ni historia. Por tanto, "debería dejarse atrás la propensión de los tres últimos regímenes políticos chilenos a iniciar transformaciones de fondo que negaban u omitían el pasado inmediatamente anterior y pretendían 'partir de cero"" 105 . Esto fue reiterado en otro documento de la misma institución al año siguiente, manifestando que "si esto es difícil o discutible en lo político y especialmente en lo económico-social, es imposible en el terreno educativo-cultural"106.

Respecto a la manera específica de implementar los cambios, se impuso el debate acerca de él o los mecanismos prácticos para realizar las adecuaciones y cambios requeridos en el tránsito educativo democrático, que se tradujo en el dilema sintetizado por el PIIE: “¿Una nueva reforma educativa?”"107. Si la modernización miraba hacia los fines, la reforma lo hacía con los medios. PIIE respondía a tal pregunta - en una lógica que

en historia de Chile. Santiago, Facultad de filosofía y humanidades, escuela de posgrado Universidad de Chile, 2005.

${ }^{101}$ PIIE, "Educación y transición democrática. Propuestas de políticas educacionales", Santiago de Chile: PIIE, octubre de1989, p. 9.

102 PIIE, 1989, op. cit., p. 9.

${ }^{103}$ Ídem.

${ }^{104}$ PIIE, 1988, op. cit., p. 31.

${ }^{105}$ Ibid, p. 41.

${ }^{106}$ PIIE, 1989, op. cit., p. 16.

${ }^{107}$ PIIE, 1988, op. cit., p. 45. 
empezaría predominar en tales círculos, suturando así la divergencia - que "sí y no", argumentando, por una parte, que "no a una reforma como el mecanismo milagroso que resuelve los problemas del sistema... no a una reforma que proviniendo del Estado, no deja espacio a la iniciativa y a la responsabilidad asumida por la sociedad civil en el cambio educacional"108. Al mismo tiempo respondían respecto de una reforma producida desde el Estado que

sí a una 'reforma abierta', es decir, a una propuesta desde el Estado que antes que ser implantada, estimule y recoja la discusión más amplia de la comunidad educacional y que, después de adoptada, sea susceptible de rectificaciones y enriquecimientos derivados de la participación de la sociedad civil y de las investigaciones evaluativas" 109 .

Con todo, esta última participación resultaba demasiado ambigua y ambivalente, sino de plano quimérica. En efecto, tal como se expondrá en las citas que siguen, la reforma debía ser "encarnada" por el mundo escolar, que estaba atravesado por una cultura antidemocrática. Por lo mismo, este, antes que "exteriorizar" sus propuestas, debía “interiorizar" las impuestas por el consenso. De acá la importancia de que los cambios en educación no se producían en plazos estrechos. De hecho, el desecho de lo que era considerado una "reforma mágica" suponía un modo particular de percibir los ritmos de cambio en esta esfera: "Los cambios profundos en educación sólo se logran en plazos largos", afirmaba el documento del PIIE de octubre de 1989, entre otros motivos, por

"la misma naturaleza de los procesos de educación formal... por la necesidad de acumulación de recursos y experiencias... por la conveniencia de insertar las transformaciones educacionales en un 'proyecto nacional de desarrollo', que necesariamente se desenvuelve en el largo plazo [y]... por el enraízamiento [sic] cultural de los procesos educativos y de las prácticas pedagógicas" ${ }^{110}$.

El remate de tal diagnóstico era evidente: "si el cambio educativo de significación es lento, se requieren políticas educacionales de larga duración", las que, para lograrlo, debían basarse en "consensos muy amplios, que no se construyen ni se encarnan aceleradamente en la población"111.

Los investigadores en general tuvieron una visión en la que el cambio educacional descansaba fundamentalmente en la dimensión cultural, la que era comprendida, en los hechos, como la internalización en el mediano y largo plazo por parte de los agentes directamente involucrados con la actividad educativa de determinadas conductas, actitudes y valores. Ello, a su vez, solo podía suceder - consideraban -, en la vida cotidiana escolar. Así, para el PIIE, "los verdaderos cambios educacionales son los que ocurren en las

\footnotetext{
108 Ibid, p. 45.

${ }^{109}$ PIIE, 1988, op. cit., p. 45.

${ }^{110}$ PIIE, 1989, op. cit., p. 17.

${ }^{111}$ Ibid.
} 
prácticas de enseñanza y aprendizaje y en las interacciones formativas que deben producirse entre educadores y educandos"112. Si ello era así, era porque, a la luz de la interpretación de los investigadores, en general la "cultura escolar" históricamente experimentada en Chile, en la que los docentes y estudiantes eran los protagonistas, resultaba reactiva a los cambios y mantenía en lo sustancial una visión y prácticas educativas añejas y que atentaban en contra de la calidad y la innovación en educación. Para Iván Núñez, por ejemplo, había que generar en el ámbito educativo una "contracultura democrática", ya que el

"régimen en 1973 se cimentó en bases culturales que estaban enraizadas en el inconsciente [sic] colectivo" 113 . Y respecto de los sectores populares, añade en otra parte, "no parecen muy conscientes de ese daño [la desigualdad educativa] ni particularmente dispuestos a movilizarse por una efectiva democratización de la educación" $" 114$.

De esta manera, pensaban, de nada serviría una reforma agendada y gestionada por la autoridad central si ella no lograba permear la cotidianeidad escolar.

\section{Conclusión}

CIDE y PIIE fueron las principales ONG's que "representaron al sector educación en el conjunto de centros de investigación y promoción social que surgieron en el país frente a la cuasi-liquidación de las ciencias sociales en la universidad"115. Si las líneas de investigación eran bastante parecidas antes del golpe, después de este se asemejaron cada vez más. Cristian Cox apunta al respecto que ambas instituciones tenían "condiciones y agendas de investigación muy similares"116. Agregamos en esta sección que los contactos no eran temáticos simplemente, ya que las mismas personas que las componían comenzaron a transitar en su adscripción institucional entre una y otra ONG. En palabras de Cox, "había mucho tráfico de ideas y de gente. Financiados por la misma agencia, dos cadenas de educación"117, cuestión que sucedió, por ejemplo, con Ernesto Schiefelbein e Iván Núñez. La cercanía también alcanzaba al desarrollo de proyectos de conjunto. En 1985, por ejemplo, las instituciones estaban asociadas a proyectos de investigación colaborativos con el Ontario Institute for Studies in Education y, por otro lado, con la Universidad Católica de Lovaina ${ }^{118}$. PIIE y CIDE, además, reforzaron el financiamiento por parte de agencias internacionales. Beatrice Ávalos plantea que las múltiples agencias que

\footnotetext{
112 Ibid.

${ }^{113}$ Iván Núñez, La gobernabilidad democrática del sector educación: relación entre investigación y política. Santiago de Chile, PIIE, 1987, p. 13.

114 Núñez, op. cit., p. 23.

115 Patricio Cariola, "La investigación educacional en América Latina", Santiago de Chile: CIDE, 1991, p. 7.

116 Entrevista al sociólogo Cristian Cox, marzo de 2015.

117 Entrevista al sociólogo Cristian Cox, marzo de 2015.

${ }^{118}$ CIDE. Memoria de 20 años, op. cit.
} 
financiaban la investigación educacional tenían como objetivo "mantener una investigación académica disidente, diferente de la oficial, en aquellos países que tenían dictaduras como Chile""119.

A lo largo de la década de 1970 y, sobre todo, de 1980, en la reflexión intelectual desarrollada en el seno de estas instituciones se produjo un reacomodo o rearticulación en los temas y los modos de abordarlos que estuvo estrechamente vinculado a las modificaciones acaecidas en la situación sociopolítica ${ }^{120}$. En este sentido, la reflexión teórica dependió en gran medida de lo que sucedía a nivel social y político, cuestión que, en una década convulsionada, condicionó el que no se produjese una reflexión educacional que lograse cristalizar en un paradigma con alto nivel de integración y blindaje teóricos. De hecho, en el momento en el que la transición a la democracia se constituyó en proceso más que probable, el discurso intelectual terminó por identificarse con la entrega de "recetas de políticas" conocidas como "ideas-fuerza" en educación.

Consideramos que un aporte del artículo ha sido comprender en concreto qué significaba en estas dos ONG's cumplir con su rol opositor: a principios de la década de 1980 consistía en oponerse práctica y teóricamente a las políticas formales de educación (y, así, al régimen completo), mientras que al mismo tiempo se levantaban propuestas de autoeducación a partir del esfuerzo de las bases sociales; a mediados de década, en intentar incidir en la educación formal tratando de abrir canales de diálogo con el régimen, mientras que a finales de la década, en impugnar toda transacción con el oficialismo -asumiendo como propias, de todas formas, muchas de las políticas educacionales instaladas por este y relevar la importancia de un consenso en el que toda idea nueva y/o divergencia en el punto de arranque del diálogo educacional quedaba atrapada en y/o marginada de la lógica de los consensos ya establecidos. Como plantea Ranciere, "la cultura consensual reconocía a los grupos de interés o de opinión la posibilidad de elegir entre las distintas opciones que los datos objetivos autorizaban, pero lo que negaba era la posibilidad de describir de otro modo los datos mismos" $" 121$.

La proyección de este modo de reflexión hacia el primer gobierno de la recientemente recuperada democracia - y en más, de la nunca acabada transición chilena - encuentra un ejemplo icónico en la figura de Juan García-Huidobro. Siendo una de los principales figuras de la teorización de la "educación popular" a principios de la década de 1980, a principios de la década siguiente asumió la responsabilidad de dirigir el P900, programa educacional estelar del nuevo gobierno, destinado a apoyar pedagógica y administrativamente a las 900 escuelas con peores resultados en la evaluación estandarizada Sistema de Medición de la

\footnotetext{
${ }^{119}$ Entrevista a Beatrice Ávalos, Ministerio de Educación, Santiago, 21 de octubre de 1999. Picazo, 2013, op. cit., p. 71.

${ }^{120}$ Cristina Moyano ha alertado acerca de las posturas que plantean un quiebre total en las lógicas de investigación pre y post-golpe. A pesar de que la Dictadura produjo la desvinculación institucional entre las demandas de investigación e intervención que el Estado requería a las ONG's, muchas de las prácticas y hábitos de investigación existentes hasta ese momento se readecuaron, antes que modificarse completamente. Cristina Moyano, "La intelectualidad de izquierda renovada en chile durante los años 80. Debates y propuestas", Revista de Historia, vol. 2 n²3, Concepción, UDEC, 2016.

${ }^{121}$ Jaques Ranciere, Política, policía, democracia. Santiago de Chile, LOM, 2006, pp. 8-9.
} 
Calidad de la Educación (SIMCE), bajo el paradigma de la focalización y endeudando al Estado con un préstamo del Banco Mundial. Posteriormente ejerció como presidente del Consejo Asesor Presidencial de la Educación generado por el gobierno del momento para enfrentar y desactivar las movilizaciones estudiantiles del año 2006 ("Revolución pingüina"), cuyo informe final no fue reconocido por las más importantes organizaciones de la sociedad civil involucradas en la educación. Por todo esto, se puede afirmar que la debilidad teórica con que estos intelectuales se enfrentaron al proceso transicional fue todo menos espuria y/o poco útil en el campo político. Por de pronto, su racionalidad "pragmática" y "consensual" les ha permitido gobernar el campo académico y político sin someter a escrutinio los propios supuestos sobre los que han operado a nivel intelectual e ideológico, aunque ello no ha sido óbice para que hayan aplicado pesada y discrecionalmente tal régimen discursivo - conformado en una efectiva política educacional - al resto de la sociedad.

Finalmente, un análisis más complejo debiese incorporar la relación que se produjo entre estas y otras ONG's vinculadas a la educación, sobre todo aquellas que divergieron en torno al proyecto educacional transicional. Una de estas, por ejemplo, afirmaba en el año del plebiscito que "no habiendo expectativas óptimas para que los movimientos populares encuentren un adecuado interlocutor estatal, ni una adecuada y efectiva 'representatividad' frente al Estado, los sectores populares tendrán que confiar en sus propias fuerzas", para, a partir de allí, "plantearse la tarea de iniciar la reconstrucción del Estado y la Sociedad desde las bases"122. Las divergencias teóricas, políticas y educacionales resultaban, a esas alturas, abismantes.

\section{Bibliografía}

\section{Fuentes impresas}

Robert Austin, The State, Literacy and de Popular Education in Chile, 1964-1990, Lexington Books, Estados Unidos, 2003.

Patricio Cariola, La investigación educacional en América Latina, Santiago de Chile, CIDE, 1991. Patricio Cariola, “¿Quién fue Patricio Cariola?”, Informativo Trimestral Proyecto MENTES ACTIVAS, $\mathrm{n}^{\circ}$ 32, Chile, Septiembre - Octubre 2004.

CIDE, Cuadernos de Educación, Santiago de Chile, CIDE, 1969-1990.

CIDE, Memoria de 20 años. Santiago de Chile, CIDE, 1982.

CIDE, Memoria 1996/1997, Santiago de Chile, CIDE, 1997.

Cristian Cox (ed.), Hacia la elaboración de consensos en política educacional: actas de una discusión. Santiago de Chile, CIDE, 1985.

122 Educación y Comunicaciones (ECO). Confiando en nuestras propias fuerzas. Taller de análisis de movimiento sociales y coyuntura. De cara a la crisis: entre el desencanto y la autofirmación, enero de 1988, p. 22. 
Cristian Cox, Osvaldo Larragaña, Iván Núñez. De los sesenta al Bicentenario: políticas, instituciones y actores del sistema escolar, v. 4. Santiago de Chile, Documento borrador Proyecto Anillo Soc 17, sin fecha.

Eduardo, Devés, El pensamiento latinoamericano en el siglo XX. Tomo II. Desde la Cepal al neoliberalismo (1950-1990). Buenos Aires, Editorial Biblos, 2003.

Francois Dosse, La marcha de las ideas, Historia de los intelectuales, historia intelectual. Valencia, Ediciones Universidad de Valencia, 2007.

ECO. Confiando en nuestras propias fuerzas. Taller de análisis de movimiento sociales y coyuntura. De cara a la crisis: entre el desencanto y la autofirmación, enero de 1988, p. 22.

Mario Garcés, "Las Ong, la educación popular y la política en los años 80: el caso de Eco, educación y comunicaciones". En, Marcelo Mella (ed.) Extraños en la noche. Intelectuales y usos políticos del conocimiento durante la transición chilena, Santiago de Chile, Ril editores, 2011.

Juan García-Huidobro. La actual política educacional: teoría y práctica, Santiago de Chile, CIDE, 1978.

Juan García-Huidobro y Sergio Martinic, "Intento de definición de la educación popular". En Juan García-Huidobro y Sergio Martinic, Educación Popular en Chile: Algunas proposiciones básicas, Santiago de Chile, CIDE, 1980.

Juan García-Huidobro, Paulo Freire y la educación de los adultos como acción cultural, Santiago de Chile, CIDE mimeo, 1982.

Juan García-Huidobro (ed.). Escuela, calidad e igualdad. Los desafíos para educar en democracia. Santiago de Chile, CIDE, 1989.

Eduardo González y Abraham Magendzo, Análisis de la educación media técnico profesional, Santiago de Chile, PIIE, 1981.

Andrea Lagos. Neoliberales, nacionalistas y estatistas: derecha política y hegemonía en el proyecto educacional del autoritarismo (1979-1988), Santiago de Chile, Tesis para optar al grado de licenciatura en historia Pontificia Universidad Católica de Chile, 1996.

Martín Miranda. "La escuela y el desafío de los derechos humanos", Revista Signos, № 2, Chile, marzo- abril de 1982.

Sergio Martinic y Horacio Walker (eds.). Profesionales en acción. Una mirada crítica a la educación popular, Santiago de Chile, CIDE, 1987.

Cristina Moyano, "Un acercamiento intelectual histórico-conceptual al concepto democracia En la intelectualidad de la izquierda renovada. Chile, 1973-1990", Revista Izquierdas, n³, Santiago de Chile, 2012.

Cristina Moyano, "ONG y conocimiento sociopolítico durante la Dictadura: la disputa por el tiempo histórico de la transición. El caso de los Talleres de Análisis de Coyuntura en ECO, 1987-1992", Revista Izquierdas, $\mathrm{n}^{\circ}$ 27, Santiago de Chile, abr. 2016.

Cristina Moyano, "La intelectualidad de izquierda renovada en chile durante los años 80. Debates y propuestas", Revista de Historia, vol. 2 n²3, Concepción, UDEC, 2016.

María Nervi, Iván Núñez Prieto. Trazos y huellas en la educación chilena del siglo XX. Santiago de Chile, Editorial Universitaria, 2013.

Sebastián Neut Aguayo. "Sin una buena educación no hay buenos trabajadores... buenos ciudadanos... buenos chilenos. El sentido de la educación en el proyecto modernizador de la Dictadura chilena (1979-1981)". Cuadernos Chilenos de Historia de la Educación, N 6, Santiago de Chile, 2016.

Sebastián Neut Aguayo. "Control ideológico en los programas secundarios transitorios en Historia y Ciencias Sociales (1974-1981)”, en Educação e Pesquisa, ahead of print Epub Aug 21, 2017. 
Iván Núñez. La gobernabilidad democrática del sector educación: relación entre investigación y política, Santiago de Chile, PIIE, 1987.

María Inés Picazo. Las políticas escolares de la Concertación durante la transición democrática. Santiago de Chile, Ediciones UDP, 2013.

PIIE. Las transformaciones educacionales bajo el régimen militar Tomos I y II. Santiago de Chile, PIIE, 1984.

PIIE. Ruptura y construcción de consensos en la educación chilena. Santiago de Chile, PIIE, 1988.

PIIE. Educación y transición democrática. Propuestas de políticas educacionales. Santiago de Chile, PIIE, 1989.

Hernán Pozo. Orientación cultural y educación chilena (1973-1981), Santiago de Chile, CIDE, 1982.

Jaques Ranciere, Política, policía, democracia. Santiago de Chile: LOM, 2006.

Jacques Revel, Las construcciones francesas del pasado. Fondo de Cultura Económica, México, 2002.

Leonora Reyes, Movimiento de educadores y construcción de política educacional en Chile (19211932 y 1977-1994). Tesis para optar al grado de doctora en historia con mención en historia de Chile. Santiago, Facultad de filosofía y humanidades, escuela de posgrado Universidad de Chile, 2005.

Claudio Suasnábar, Intelectuales, exilios y educación. Producción intelectual e innovaciones teóricas en educación durante la última dictadura. Buenos Aires, Prohistoria, 2013.

\section{Entrevistas}

Cristian Cox. Entrevista realizada en marzo de 2015 en Santiago de Chile. Entrevistador: Sebastián Neut Aguayo.

Jacqueline Gysling. Entrevista realizada en enero de 2015 en Santiago de Chile. Entrevistador: Sebastián Neut Aguayo. 